\title{
AN INVESTIGATION OF BRUCELLOSIS KNOWLEDGE, ATTITUDE AND PRACTICE AMONG LIVESTOCK OWNERS IN THE WEST BANK
}

\author{
Elena Awwad, ${ }^{1}$ Osama Awwad, ${ }^{2}$ Mohammad Farraj, ${ }^{3}$ Tamer Essawi, ${ }^{4}$ Kamel Adwan, \\ Assad Manasra, ${ }^{6}$ Stelian Baraitareanu, ${ }^{7}$ Maria Rodica Gurau, ${ }^{8}$ Doina Danes ${ }^{9}$
}

\begin{abstract}
Brucellosis is endemic in Palestine and therefore since 1998 a national program of brucellosis control has been launched. In the traditional breeding area of small ruminants, brucellosis is often reported in humans, mainly as a food borne disease. Any control strategy requires a well-functioning surveillance system, the co-operation with owners and a sustainable financial support. The aim of this study is sizing up of the current situation of knowledge, of the attitude and practice (KAP) regarding brucellosis, among sheep and goat farmers. A cross-sectional survey was conducted in 118 participants through an anonymous questionnaire to assess to which extent the flock owners are familiar with the knowledge and practices related to brucellosis of small ruminants. The designs of the questionnaire consider the implementation of KAP. Results shown that farmers, independent on their education, heard about brucellosis (100\%) and all of them consider the washing of hands as necessary after close contact with animals or their products, and animal vaccination as being necessary to prevent brucellosis. Despite the educational level, almost all owners are aware about the risk of exposure of their family to animals infected with Brucella: they are considering the heating of cheese at boiling point and the use of gloves, as appropriate practices to reduce the exposure to Brucella. Great majorities of the participants $(89.8 \%)$ have good knowledge about the transmission of Brucella from animals to humans, but only $37.3 \%$ correctly answered about the transmission of brucellosis by drinking raw milk, eating unpasteurized cheese, eating raw meat, liver, spleen and kidney or by contact with an aborted foetus and placenta fluid. Referring to the brucellosis' prevention, $83 \%$ answered that boiling of milk and cheese and wearing of gloves when handling an aborted foetus could prevent it: these answers fit with the level of knowledge. From the questioned owners, $28.8 \%$ knew that boiling the milk affect his nutritive value; $84.7 \%$ think that owners of animals and their families are more exposed to brucellosis and $11.9 \%$ of their families have been diseased. Relative good general knowledge of owners about brucellosis was recorded, but high-risk behaviors still exist. Awareness campaigns on the control and prevention of the brucellosis are success stories, and government agencies should continue the public education.
\end{abstract}

UDC Classification: 614.9; DOI: http://dx.doi.org/10.12955/cbup.v5.1068

Keywords: KAP, investigation, awareness, prevention, sheep, goat, Palestine

\section{Introduction}

Globally, brucellosis is still an important issue of the public health authorities (Doganay \& Aygen, 2003; Gul \& Khan, 2007). In the traditional breeding area of small ruminants, brucellosis is often reported in humans, mainly as a food borne disease - by ingestion of raw dairy products, or as an occupational disease - by exposure to infected livestock (Sanco, 2001; Doganay \& Aygen, 2003; Zvizdic et al, 2006; Kaoud et al, 2010; Saleem et al, 2010). This infection is also associate with high economic losses, as a result of abortions, weak offspring, reduced milk production and the commercial banning of the products (WHO, 1998; FAO, 2010). Many countries are carrying on programs of brucellosis eradication, but they have not yet fully succeeded. Any control strategy requires a wellfunctioning surveillance system, the co-operation with owners and sustainable financial support (Refai, 2002; FAO, 2010). The brucellosis control program must consider public health education as an essential activity performed within this framework, among all the concerned population, and underlining the key factors in the disease spreading (WHO, 2009; FAO, 2010).

Public health education is a difficult and extremely complex task, which includes culture, beliefs, traditions, educational level, social status, occupation, and age. Therefore, health education programs should be firstly aimed at physicians, veterinarians and farmers. These groups should be directed not

\footnotetext{
${ }^{1}$ Faculty of Veterinary Medicine, University of Agronomic Science and Veterinary Medicine of Bucharest, Romania; Central Veterinary Laboratory, General Directorate of Veterinary Services and Animal Health, Ramallah, Ministry of Agriculture, Palestine, eleenaawwad@yahoo.com

${ }^{2}$ Central Veterinary Laboratory, General Directorate of Veterinary Services and Animal Health, Ramallah, Ministry of Agriculture, Palestine, eleenaawwad@yahoo.com

${ }^{3}$ Master Program in Clinical Laboratory Science (MCLS), Birzeit University, Palestine, mfarraj@birzeit.edu

${ }^{4}$ Master Program in Clinical Laboratory Science (MCLS), Birzeit University, Palestine, tessawi@ birzeit.edu

${ }^{5}$ Department of Biology and Biotechnology, An-Najah National University, Nablus, Palestine, adwank@ yahoo.com

${ }^{6}$ Central Veterinary Laboratory, General Directorate of Veterinary Services and Animal Health, Ramallah, Ministry of

Agriculture, Palestine, vet_asad@yahoo.com

${ }^{7}$ Faculty of Veterinary Medicine, USAMV B, Romania, doruvet@gmail.com

${ }^{8}$ Faculty of Veterinary Medicine, USAMV B, Romania, otelea_maria@yahoo.com

${ }^{9}$ Faculty of Veterinary Medicine, USAMV B, Romania, danes.doina@ gmail.com
} 
only at specific measures, but should also emphasize the responsibility of their own and community safety by defining their own problems, to understand what can be done to deal with it using their own resources and external support and to decide appropriate resolutions. Secondly, the whole community should be involved through health education in schools, in the workplace and in all the population (WHO, 2009).

The aim of this study is sizing up of the current situation of knowledge, of the attitude and practice (KAP) regarding brucellosis, among sheep and goat farmers, after 15 years of implementation of this project. This study showed relative good general knowledge of owners about brucellosis, but they still have high-risk behavior. It is therefore recommended that government agencies pay more attention to public education, by creating awareness campaigns on the control and prevention of brucellosis, as one of the most important steps in the eradication of brucellosis.

\section{Material and Methods}

Area of study and population

West Bank is the part of Palestine with a population of 2754722 . The terrain is mostly rugged dissected upland, some vegetation in the west, but somewhat barren in the east. There are few natural resources in the area except the highly arable land, which comprises $27 \%$ of the land area of the region. It is mostly used as permanent pastures (32\% of arable land) and seasonal agricultural uses $(40 \%)$ (CIA, 2014). The value of the agricultural sector is about $60 \%$ of the plant and $40 \%$ of the livestock production. (MOA, 2013). The study was performed in seven districts of the West Bank territory (Palestine): Jenin, Tubas, Nablus, Jerusalem, Bethlehem, Hebron and Dura. These districts have been selected considering the high density of humans, animal and of familial farming of sheep and goats. The query was done only on livestock owners, which not only consume, but also sell their dairy production. The livestock sector is dominated by small ruminants: 732,399 sheep and 240,136 goats. There are also 39,625 cattle, 1,506 camels and 3,603 horses. In poultry farms, there are 36.5 million layers and 1.6 million broilers. The number of traditional and modern beehives is 44,278 and the total quantity of fish is 1,318 tons. A quarter of livestock owners $(25.3 \%)$ is basing their livelihood on agriculture (MOA, 2011; MOA, 2013; EU, 2013).

Study design

We carried out an anonymous questionnaire survey to assess to which extent the flock owners were familiar with the knowledge and practices related to brucellosis of small ruminants. The designs of the questionnaire consider the implementation of KAP (WHO, 2009). The questionnaire was submitted to 118 flock owners.

\section{Ethic consideration}

All participants have been informed about the purpose and methods of the study. Owners agreed to participate voluntarily and anonymously.

Statistical analyses

The provided data were analyzed with the software SPSS (version 20, IBM, Chicago, IL, USA), by descriptive statistic, ordinal and binary logistic regression models and correlation between groups. To determine the relationship between associations two or more variables was used with a chi-square test with $p$ value of 0.05 considered as the level of significance. Using the binary version of each category (of knowledge) as a response, a logistic regression models was fitted to investigate potential predictions and associations between the level of knowledge about brucellosis, the practice of drinking dairy products, boiling of cheese and other important predictor variables. The correct answer was considered as code: "0", don't know: "1", and not correct was coded: "2". Multivariate logistic regression analyses were performed separately to determine the predictors of knowledge, and the adoption of management practices at a farm level. Also, an ANOVA was used as a homogeneity test (significance more than 5\%) which showed that present equal deviation between variables and significance less than 5\% in its mean and present differences between the types of variables.

\section{Results and Discussion}

The Table 1 presents the socio-cultural pattern of respondents: the most prevalent profile is "male, from rural area, medium education level". 


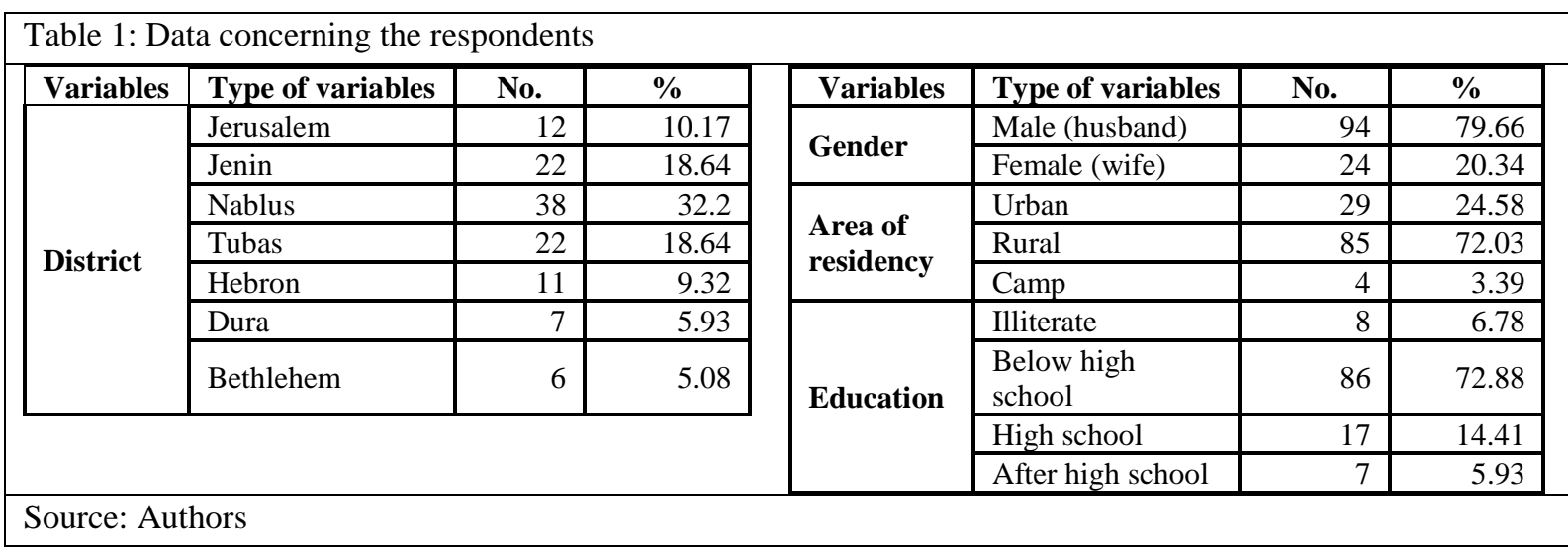

The respondents have been answered to basic questions, related to their knowledge concerning: diseases transmitted from animals to humans, minimal personal hygiene rules, the risks of the processing or of the ingesting of animal products (Table 2).

Our study shows that farmers, independent on their education, heard about brucellosis (100\%). All respondents consider the washing of hands as necessary after closed contact with animals or their products. They are considering animal vaccination as being also necessary to prevent brucellosis. Other aspects of the KAP study had a significant difference of level of education and knowledge (Table 2).

The next questions targeted the "beliefs" of respondents in terms of their insight about: occupational exposure, cooking practices, the personal hygiene, the vaccination and the specific knowledge, on brucellosis (Table 3 ).

Despite the educational level, almost all owners are aware about the risk of exposure of their family to animals infected with Brucella: they are considering the heating of cheese at boiling point and the use of gloves, as appropriate practices to reduce the exposure to Brucella.

\begin{tabular}{|c|c|c|c|}
\hline Variables & Type of variables & No. & $\%$ \\
\hline \multirow[t]{2}{*}{ Have you heard about brucellosis? } & Yes & 118 & 100 \\
\hline & No & 0 & 0.00 \\
\hline \multirow{3}{*}{$\begin{array}{l}\text { Is this disease transmittable from } \\
\text { animal to man? }\end{array}$} & Yes & 106 & 89.83 \\
\hline & Don't know & 6 & 5.08 \\
\hline & No & 6 & 5.08 \\
\hline \multirow{3}{*}{$\begin{array}{l}\text { From which animal is disease } \\
\text { transmitted to man? }\end{array}$} & Sheep, goat, cattle & 108 & 91.53 \\
\hline & Don't know & 10 & 8.47 \\
\hline & Other animals & 0 & 0.00 \\
\hline \multirow[t]{3}{*}{$\begin{array}{l}\text { The disease is transmitted from } \\
\text { animals to man by: }\end{array}$} & $\begin{array}{l}\text { Drinking unpasteurized milk, eating raw cheese, contact } \\
\text { with aborted foetuses or placenta fluids eating meat, liver, } \\
\text { spleen not well cooked }\end{array}$ & 44 & 37.29 \\
\hline & Insects bites & 3 & 2.54 \\
\hline & All choose & 71 & 60.17 \\
\hline \multirow{3}{*}{$\begin{array}{l}\text { Do you think that Brucellosis could be } \\
\text { caused by drinking fresh milk without } \\
\text { boiling? }\end{array}$} & Yes & 102 & 86.44 \\
\hline & Don't know & 9 & 7.63 \\
\hline & No & 7 & 5.93 \\
\hline \multirow{3}{*}{$\begin{array}{l}\text { Do you think that boiling the milk } \\
\text { affects its nutritive value? }\end{array}$} & Yes & 34 & 28.81 \\
\hline & Don't know & 19 & 16.10 \\
\hline & No & 65 & 55.08 \\
\hline \multirow{3}{*}{$\begin{array}{l}\text { Do you think that eating fresh raw } \\
\text { cheese may cause Brucellosis? }\end{array}$} & Yes & 76 & 64.41 \\
\hline & Don't know & 26 & 22.03 \\
\hline & No & 16 & 13.56 \\
\hline \multirow[t]{3}{*}{ The disease can be prevented by: } & $\begin{array}{l}\text { Boiling milk, cheese and wearing gloves when handling } \\
\text { aborted fetus }\end{array}$ & 98 & 83.05 \\
\hline & Eating honey & 2 & 1.69 \\
\hline & All choose & 18 & 15.25 \\
\hline
\end{tabular}


Even if the questions previously assessed proved a satisfactory level of knowledge and an appropriate attitude toward brucellosis, the practices are far to be in accordance.

The great majorities of the participants $(89.8 \%)$ have good knowledge about the transmission of Brucella from animals to humans, but only $37.3 \%$ correctly answered about the transmission of brucellosis by drinking raw milk, eating unpasteurized cheese, eating raw meat, liver, spleen, and kidney or by contact with aborted foetuses and placenta fluid. Referring to the brucellosis' prevention, $83 \%$ answered that boiling of milk and cheese and wearing of gloves when handling aborted foetuses could prevent it: these answers fit with the level of knowledge, as revealed in table 2. From the questioned owners, $28.8 \%$ knew that boiling the milk affects its nutritive value; $84.7 \%$ think that owners of animals and their families are more exposed to brucellosis (Table 3), and $11.9 \%$ of their families have been diseased (Table 4).

\begin{tabular}{|c|c|c|c|}
\hline Variables & $\begin{array}{c}\text { Type of } \\
\text { variables }\end{array}$ & No. & $\%$ \\
\hline \multirow{3}{*}{$\begin{array}{l}\text { Do you think that animal owners and their families are more exposed to } \\
\text { Brucellosis? }\end{array}$} & Yes & 100 & 84.75 \\
\hline & Don't know & 11 & 9.32 \\
\hline & No & 7 & 5.93 \\
\hline \multirow[t]{3}{*}{ Do you think that boiling cheese is necessary before consuming? } & Yes & 111 & 94.07 \\
\hline & Don't know & 5 & 4.24 \\
\hline & No & 2 & 1.69 \\
\hline \multirow[t]{3}{*}{ Do you think that using gloves when you deal with animals is necessary? } & Yes & 109 & 92.37 \\
\hline & Don't know & 5 & 4.24 \\
\hline & No & 4 & 3.39 \\
\hline \multirow{3}{*}{$\begin{array}{l}\text { Do you think that washing hands is necessary after closed contact with } \\
\text { animals or their products? }\end{array}$} & Yes & 118 & 100 \\
\hline & Don't know & 0 & 0.00 \\
\hline & No & 0 & 0.00 \\
\hline \multirow{3}{*}{ Do you think that animal vaccination is necessary to prevent Brucellosis? } & Yes & 118 & 100 \\
\hline & Don't know & 0 & 0.00 \\
\hline & No & 0 & 0.00 \\
\hline \multirow[t]{2}{*}{ Do you think that you need more information about Brucellosis? } & Yes & 103 & 87.29 \\
\hline & No & 15 & 12.71 \\
\hline
\end{tabular}

Brucella accidentally infects humans. The pathogen infects directly or is mediated, either through injured/broken skin, a mucous membrane or by ingestion of contaminated products, mainly fresh milk products. The greatest risk of infection is through direct contact with aborted animals, during lambing or the kidding period. Products such as unpasteurized milk and homemade cheese are the main source of infection for people who do not have direct contact with animals. Brucellosis is primarily an occupational risk in exposed professions, veterinarians, farmers, laboratory technicians, abattoir workers, and others who work with animals and their products. People living near infected premises may also be infected (Sanco, 2001; Corbel, 2006; Rumosa Gwaze et al., 2009; Smits, 2012). Therefore, the knowledge of livestock owners regarding brucellosis play an important role in the taking of preventive measures that could stop or reduce the spreading of the disease. The level of knowledge could be monitored through the KAP survey, as a quantitative method, with questions formatted in standardized questionnaires that provides access to information. KAP surveys reveal misconception, which represent obstacles to the activities and can raise potential barriers to behavior change (WHO, 2009; USAID, 2011; Macias \& Glasauer, 2014).

Knowledge is the information of which a person, group of people, organization or other entity becomes aware of something and improves his attitude and practice through learning, education or by experience, perception or reflection. Attitude is the mental state about an issue or subject and is manifested through the practice or behavior of a person or organization. Practice generally depends on knowledge, economic stability and the socio-economic condition of farmers. The poor knowledge about brucellosis and the natives' population is interfering in Brucellosis' control and its spread (WHO, 2009; Addo et al., 2011; USAID, 2011; Khan et al., 2013). In Palestine, since 1998 the Ministry of Agriculture in cooperation with the UNDP/PAPP organization started the implementation of the Brucellosis Control Program, financially supported by Argentina, Japan and Spain, and technically by the WHO, FAO and OIE organizations. 


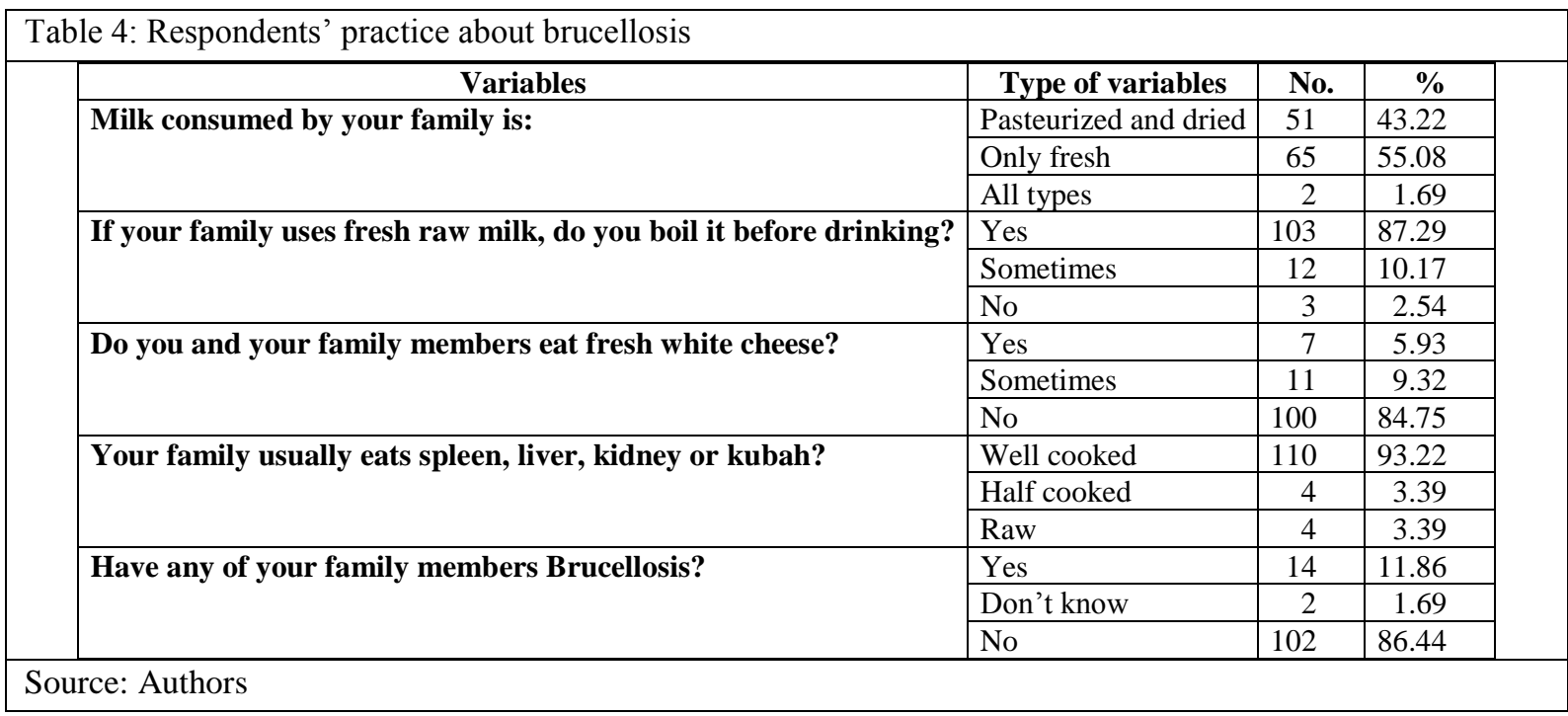

This study revealed that only $46.6 \%$ participants have information about brucellosis, more than half (53.4\% participants) consume raw milk and $89 \%$ of respondents consider the use of gloves while dealing with animals (Ramlawi, 2000). This project improved the control strategy, proposing the mass vaccination of small ruminants and all other activities, including the awareness campaigns about brucellosis among all population. Since 1999 the Brucellosis Control Program has been implemented at a national level (UNDP, 2010). In our study, the status of knowledge, attitude and practices was assessed through discussion with farmers and gave us a general picture for the 15 years of the brucellosis control: the implementation of Brucellosis Control Program generated many achievements, including the change of farmers' mentality. Before starting Brucellosis Control Program less than 50\% of owners heard about brucellosis as being a dangerous infectious disease, but in the current study all of them are aware (100\%). Most of the participants (87.3\%) have been interested and requested more information about education in public health. The interest manifested toward knowledge by the respondents is a promising factor for early improvement of practices of animal husbandry and milk processing; this general interest acts as a factor for reducing exposure, not only to Brucella spp, but also to other zoonotic pathogens.

The current study found that the level of education was an important predictor and was positively associated with the adoption of preventive practices: this correlation was observed in many KAPs surveys (Xiang et al., 2010; Holt et al., 2011; Khan et al., 2013; Lindahl et al., 2015). This study can help to develop appropriate policies of preventive measures by improving the knowledge and practice of farmers in sanitation, hygiene and waste management.

\section{Conclusion}

This study showed relative good general knowledge of owners about brucellosis, but they still perform high-risk behavior. It is therefore recommended that government agencies pay more attention to public education, by creating awareness campaigns on the control and prevention of brucellosis, as one of the most important steps in the eradication of brucellosis.

\section{References}

Addo, K. K., Mensah, G. I., Nartey, N., Nipah, G. K., Mensah, D., Aning, K. H., \& Smits, H. L. (2011). Knowledge, Attitudes and Practices (KAP) of Herdsmen in Ghana with respect to Milk-Borne Zoonotic Diseases and the Safe Handling of Milk. Journal of Basic and Applied Scientific Research, 1(10), 1556-1562.

CIA. (2014). West Bank. Retrieved from https://www.cia.gov/library/publications/the-world-factbook/geos/we.html Corbel, M. J. (2006). Brucellosis in human and animals. Retrieved from http://www.who.int/csr/resources/publications/Brucellosis.pdf

Doganay, M., \& Aygen, B. (2003). Human brucellosis: an overview. International Journal of Infectious Diseases, 7(3), 173 182. DOI:10.1016/S1201-9712(03)90049-X

EU. (2013). The European Union programme in support of agriculture and livestock based livelihoods in the West Bank. Retrieved from https://eeas.europa.eu/sites/eeas/files/20140401_agriculturebrochure_en.pdf

FAO. (2010). Brucella melitensis in Eurasia and the Middle East. Retrieved from http://www.fao.org/docrep/012/i1402e/i1402e00.pdf 
Gul, T., \& Khan, A. (2007). Epidemiology and epizootology of brucellosis: A review. Pakistan Veterinary Journal, 27(3), 145-151.

Rumosa Gwaze, F., Chimonyo, M., \& Dzama, K. (2009). Communal goat production in Southern Africa: a review. Tropical Animal Health and Production, 41(7), 1157-1168. DOI:10.1007/s11250-008-9296-1

Holt, H. R., Eltholth, M. M., Hegazy,Y. M., El-Tras, W. F., Taye, A. A., \& Guitian, J. (2011). Brucella spp. infection in large ruminants in an endemic area of Egypt: cross-sectional study investigating seroprevalence, risk factors and livestock owner's knowledge, attitudes and practices (KAPs). BMC Public Health, 11, 341. DOI:10.1186/1471-2458-11-341

Kaoud, H. A., Zaki, M. M., El-Dahshan, A. R., \& Nasr, S. A. (2010). Epidemiology of brucellosis among farm animals. Nature and Science, 8(5), 190-197.

Khan, H. A. A., Akram, W., Shad, S. A., Razaq, M., Naeem-Ullah, U., \& Zia, K. (2013). A cross sectional survey of knowledge, attitude and practices related to house flies among dairy farmers in Punjab Pakistan. Journal of Ethnobiology and Ethnomedicine, 9, 18. DOI:10.1186/1746-4269-9-18

Lindahl, E., Sattorov, N., Boqvist, S., \& Magnusson, U. (2015). A study of knowledge, attitudes and practices relating to brucellosis among small-scale dairy farmers in an urban and peri-urban area of Tajikistan. PLoS One, 10(2), e0117318. DOI:10.1371/journal.pone.0117318

Macias, Y. F., \& Glasauer, P. (2014). Guidelines for assessing nutrition-related Knowledge, Attitudes and Practices. Retrieved from http://www.fao.org/3/a-i3545e.pdf

MOA. (2011). Action Plan of the National Agricultural Strategy "Shared Vision" 2011-2013. Palestinian National Authority. Retrieved from www.apis.ps/up/1323689642.pdf

MOA. (2013). National Priority Interventions in the Agricultural Sector 2013-2015. Palestinian National Authority. Retrieved from www.palestine-diplo.com/IMG/.../national.docx

Ramlawi, A. (2000). Preventive Medicine Team. Brucellosis Prevention and Control Program: (KAP) Knowledge-Attitude and Practice, Palestinian National Authority, Ministry of Health

Refai, M. (2002). Incidence and control of brucellosis in the Near East region. Veterinary Microbiology, 90(1-4), 81-110. DOI:10.1016/S0378-1135(02)00248-1

Saleem, M. N., Boyle, S. M., \& Sriranganathan, N. (2010). Brucellosis: a re-emerging zoonosis. Veterinary Microbiology, 140(3-4), 392-398. DOI:10.1016/j.vetmic.2009.06.021

Sanco (2001). Brucellosis in sheep and goats (Brucella melitensis). Retrieved from https://ec.europa.eu/food/sites/food/files/safety/docs/sci-com_scah_out59_en.pdf

Smits, H. L. (2012). Control and prevention of brucellosis in small ruminants: time for action. Veterinary Record, 170(4), 9798. DOI:10.1136/vr.e666

UNDP. (2010). Palestinian Brucellosis Control Project, Annual Progress Report, Retrieved from www.papp.undp.org/en/fsh/54948.pdf

USAID. (2011). The KAP Survey Model (Knowledge, Attitudes, and Practices). Retrieved from https://www.springnutrition.org/sites/default/files/publications/annotation/spring_kap_survey_model.pdf

WHO. (1998). Human and animal brucellosis: Epidemiological Surveillance in the MZCP Countries. The MZCP report on the third workshop on human and animal brucellosis epidemiological surveillance in the MZCP countries. 1998 May 4-5; Damascus, Syrian Arab Republic. Athens: World Health Organization Mediterranean Zoonoses Control Programme. WHO. (2009). A guide to developing knowledge, attitude and practice surveys. Retrieved from http://apps.who.int/iris/bitstream/10665/43790/1/9789241596176_eng.pdf

Xiang, N., Shi, Y., Wu, J., Zhang, S., Ye, M., Peng, Z., Zhou, L., Zhou, H., Liao, Q., Huai, Y., Li, L., Yu, Z., Cheng, X., Su, W., Wu, X., Ma, H., Lu, J., McFarland, J., \& Yu, H. (2010). Knowledge, attitudes and practices (KAP) relating to avian influenza in urban and rural areas of China. BMC Infectious Diseases, 10, 34. DOI:10.1186/1471-2334-10-34

Zvizdic, S., Cengic, D., Bratic, M., Mehanic, S., Pinjo, F., \& Hamzic, S. (2006). Brucella melitensis review of the human infection case. Bosnian Journal of Basic Medical Sciences, 6(1), 15-18. 